\title{
Complex sleep apnea syndrome
}

This article was published in the following Dove Press journal:

Patient Preference and Adherence

2 July 2013

Number of times this article has been viewed

\section{Juan Wangl,* \\ Yan Wangl,* \\ Jing Feng ${ }^{1,2}$ \\ Bao-yuan Chen' \\ Jie Cao'}

'Respiratory Department of Tianjin Medical University General Hospital, Tianjin, People's Republic of China; ${ }^{2}$ Division of Pulmonary and Critical Care Medicine, Duke University Medical Center, Durham, NC, USA

*The first two authors contributed equally to this work
Correspondence: Jing Feng Respiratory Department of Tianjin Medical University General Hospital, Tianjin 300052,

People's Republic of China Email zyyhxkfj@I26.com; jing.feng2@duke.edu
Abstract: Complex sleep apnea syndrome (CompSAS) is a distinct form of sleep-disordered breathing characterized as central sleep apnea (CSA), and presents in obstructive sleep apnea (OSA) patients during initial treatment with a continuous positive airway pressure (CPAP) device. The mechanisms of why CompSAS occurs are not well understood, though we have a high loop gain theory that may help to explain it. It is still controversial regarding the prevalence and the clinical significance of CompSAS. Patients with CompSAS have clinical features similar to OSA, but they do exhibit breathing patterns like CSA. In most CompSAS cases, CSA events during initial CPAP titration are transient and they may disappear after continued CPAP use for 4 8 weeks or even longer. However, the poor initial experience of CompSAS patients with CPAP may not be avoided, and nonadherence with continued therapy may often result. Treatment options like adaptive servo-ventilation are available now that may rapidly resolve the disorder and relieve the symptoms of this disease with the potential of increasing early adherence to therapy. But these approaches are associated with more expensive and complicated devices. In this review, the definition, potential plausible mechanisms, clinical characteristics, and treatment approaches of CompSAS will be summarized.

Keywords: complex sleep apnea syndrome, obstructive sleep apnea, central sleep apnea, apnea threshold, continuous positive airway pressure, adaptive servo-ventilation

\section{Introduction}

The recognition of sleep apnea syndrome as a common and serious public health problem has become widespread. Generally speaking, most patients with sleep apnea syndrome are diagnosed with obstructive sleep apnea syndrome (OSAS). Continuous positive airway pressure (CPAP) is the first-line noninvasive treatment for OSAS and can efficiently suppress obstructive respiratory events. However, it has long been noted in sleep disorder clinics that some patients presenting predominantly with obstructive sleep apnea (OSA) at baseline experience accompanying central sleep apnea (CSA) events after tracheostomy or application of CPAP. ${ }^{1,2}$ The term "treatment-emergent central apnea" was previously used to describe this phenomenon. Then, Gilmartin et $\mathrm{al}^{3}$ introduced "complex sleep-disordered breathing," a new name for this, and Morgenthaler et $\mathrm{al}^{4}$ termed this type of sleep-disordered breathing as "complex sleep apnea syndrome." Recently, the term "complex sleep apnea syndrome" (CompSAS) has gained popularity. However, considerable controversy exists regarding CompSAS. ${ }^{5,6}$ Some researchers recognize the disease CompSAS as a unique entity. On the other hand, some researchers think CompSAS is not a disease but comprises a vaguely defined group of entities with varying etiologies, 
and many of its forms are generally innocuous and selflimited. A number of entities are frequently lumped into the term "complex apnea": eg, inadequate or excessive titration, substantial mask leak leaving residual events, residual sleepiness on CPAP, and sleep transition apneas upon CPAP initiation. Recently, CompSAS has attracted attention from the sleep medicine community. In this review, the definition, potential plausible mechanisms, and clinical characteristics, including treatment approaches for CompSAS, will be summarized.

\section{Definition}

The definition of CompSAS is diverse in the literature. In most, sleep apnea initially manifests as an obstructive component, but the presentation of frequent central components or a predominant Cheyne-Stokes respiration pattern after the removal of upper airway obstruction has been defined as CompSAS. ${ }^{3,4,7}$ Using this definition, patients are said to have CompSAS when their diagnostic polysomnogram shows them to have OSA, but during subsequent therapy that eliminates events defining OSA, the residual central apnea index (CAI) is five or more events per hour or a Cheyne-Stokes respiration pattern that becomes prominent and disruptive.

In the US, the Centers for Medicare and Medicaid Services in the Durable Medical Equipment Regional Carrier Region D Supplier Manual (CMS Pub 100-03, Medicare National Coverage Determinations Manual, Chapter 1, Section 280.1) states: "Complex sleep apnea (CompSA) is a form of central apnea specifically identified by the persistence or emergence of central apneas or hypopneas upon exposure to CPAP or an E0470 device when obstructive events have disappeared."

Sometimes the appearance of central sleep-disordered breathing has also been seen with non-CPAP treatments for OSA, including tracheostomy, maxillomandibular advancement surgery, and mandibular advancement device. Fletcher ${ }^{8}$ reported on a patient who 4 years earlier underwent curative tracheostomy for severe OSA and then had a $23 \mathrm{~kg}$ weight gain. This patient redeveloped hypersomnolence and, when restudied, apneas of similar frequency, duration, and depth of desaturation reappeared but were now totally central in origin. Kuźniar et $\mathrm{al}^{9}$ reported on two patients with CompSAS who had similar phenomena when treated with an oral appliance. In an observation by Corcoran et al, ${ }^{10}$ a 38 -year-old male who developed marked CSA 3 months after a maxillomandibular advancement surgery for moderate OSA was reported. In a later report, Goldstein and Kuzniar ${ }^{11}$ described a patient with
OSA and new-onset CSA after nasal and sinus surgery. So the definition of CompSAS may be broadened to include diagnosis of CompSAS in non-CPAP-treated patients who are managed with, for example, a dental appliance or a surgical procedure.

\section{Mechanisms}

Chemoreceptor inputs (medullary neurons responding to $\mathrm{CO}_{2}$ via shifts in $\mathrm{H}^{+}$concentration and peripherally at the carotid body via $\mathrm{PaO}_{2}$ and $\mathrm{PaCO}_{2}$ ) play a key role in modulating ventilation. ${ }^{12}$ In most cases, the major determinant of minute ventilation is $\mathrm{PaCO}_{2} . \mathrm{PaCO}_{2}$ is tightly maintained near $40 \mathrm{mmHg}$ during wakefulness. During sleep, the chemosensitivity to both $\mathrm{CO}_{2}$ and $\mathrm{O}_{2}$ falls and varies with sleep stage. A mean $\mathrm{PaCO}_{2}$ of $45 \mathrm{mmHg}$ occurs during stable sleep. Behavioral influences and neurocompensatory responses strongly inhibit apnea, even in the presence of marked decreases in $\mathrm{PaCO}_{2}$ during wakefulness, but this is not the case during sleep. Indeed, during sleep, all individuals are susceptible to breathing cessation when $\mathrm{PaCO}_{2}$ falls below a critical threshold known as the apnea threshold. ${ }^{13-15}$ The apnea threshold is usually $2-6 \mathrm{mmHg}$ below the eucapnic sleeping $\mathrm{PaCO}_{2}$ level. This typically equates to the wakefulness eucapnic $\mathrm{PaCO}_{2}$ level or marginally lower. The ventilatory output to a given change in $\mathrm{PaO}_{2}$ or $\mathrm{PaCO}_{2}$ can vary greatly among individuals and with disease status. Highly sensitive chemoresponses can place an individual at risk for unstable breathing patterns, because these individuals "over-respond" to small changes in chemical stimuli. For example, to a given increase in $\mathrm{PaCO}_{2}$, an individual with high chemosensitivity will respond by increasing ventilation to a greater extent than an individual with low chemosensitivity. This increased ventilation will continue until the resultant reduction in $\mathrm{PaCO}_{2}$ is detected by the chemoreceptors. Thus, individuals with high chemoresponsiveness will hyperventilate markedly, lowering $\mathrm{PaCO}_{2}$ below the eucapnic level and leading to hypopnea and potential apnea. ${ }^{16-18}$ This may be explained in the context of so-called loop gain. In fact, a high loop gain may be the essential underlying mechanism for all central disordered breathing patterns occurring during sleep, including CompSAS. "Loop gain" is an engineering term that is a measure of the stability or instability in the ventilatory control system. Loop gain is mathematically defined as the ratio of a corrective response (eg, hyperpnea) to a disturbance (eg, apnea). If corrective responses are greater than the disturbance (loop gain $>1$ ), then small disturbances can lead to self-sustaining oscillations. Those 
with high loop gain are prone to instability, whereas those with low loop gain are quite resistant to periodic breathing. ${ }^{19-22}$ Younes et $\mathrm{al}^{23}$ assessed ventilatory loop gain with the proportional-assist ventilation technique. In this study, individuals with high loop gain develop periodic breathing with minimal proportional-assist ventilation support when those with low loop gain do not develop periodic breathing, even with considerable proportional-assist ventilation support. In fact, currently, the exact mechanisms of CompSAS are not well understood. Presumably, there must be dual causation that includes anatomic and physiologic vulnerability to OSA plus a central breathing control instability leading to chemo-reflex dysfunction. ${ }^{24}$ Among this process, high loop gain may be required. In some cases of CompSAS, we can see a typical crescendodecrescendo respiratory pattern indicative of a high loop gain state. ${ }^{4}$

Though we have loop gain theory as a basic mechanism hypothesis for the ventilatory overshoot in CompSAS, proximity of sleep apneic threshold to awake $\mathrm{PaCO}_{2}$, low arousal threshold, and incomplete control of obstruction have all been postulated to contribute to the development of CompSAS under various clinical circumstances. ${ }^{25}$

Changes in $\mathrm{CO}_{2}$ excretion occur with the relief of upper airway obstruction. ${ }^{26} \mathrm{~A}$ high upper airway resistance can dampen the ventilatory control system, reducing the efficiency of $\mathrm{CO}_{2}$ excretion. With the application of CPAP, the upper airway is opened by effectively removing a large resistance from the respiratory system. The efficiency of $\mathrm{CO}_{2}$ excretion is improved, and thus hypocapnia can result. If the resulting $\mathrm{PaCO}_{2}$ falls below the $\mathrm{CO}_{2}$ apnea threshold, then cessation in respiratory effort may be expected. Over the course of several days to weeks, the $\mathrm{CO}_{2}$ apnea threshold may or may not improve, resulting in resolution of the central apnea or not, respectively. ${ }^{16}$ Several other factors have also been proposed for the emergence of central apnea following the initiation of CPAP therapy. Over titration of CPAP is thought to lead to central apnea, although the mechanisms are poorly understood. One reason may be the activation of lung stretch receptors, which may inhibit central respiratory motor output. Another possibility is that washing out of $\mathrm{CO}_{2}$ from the anatomical dead space may occur if mask leak or mouth breathing develop at high CPAP levels. Initiation of CPAP may worsen sleep quality, and transitions from sleep to wake can contribute to central apneas associated with state instability ${ }^{27}$ In such cases, the ventilatory response to arousal can drive the $\mathrm{PaCO}_{2}$ below the $\mathrm{CO}_{2}$ apnea threshold, yielding central apnea during subsequent sleep. CPAP intolerance secondary to an elevated nasal resistance may relate to frequent arousals, which could presumably contribute to the increase in CSA. ${ }^{28}$ The potential mechanisms of CompSAS that are available are summarized in Figure 1.

\section{Risk factors, prevalence, and clinical characteristics}

Common risk factors for CSA include systolic heart failure, atrial fibrillation, cerebrovascular diseases, and use of opioid drugs, which may also be the risk factors associated with CompSAS. ${ }^{29-31}$ Bitter et al ${ }^{32}$ performed a cohort study of patients with congestive heart failure (CHF) and CompSAS. Of 192 patients with CHF and moderate to severe OSA undergoing CPAP titration, 34 (18\%) developed CompSAS. The definition of CompSAS used in this study was considerably more demanding than in previously published series. In this study, CompSAS was defined as $\geq 15$ episodes of central apnea or periodic breathing per hour during CPAP titration and $<10 \%$ of events being obstructive. An additional 36 patients (19\%) presented with mild CSA (5-14/hour), who did not meet the criterion in this article. The prevalence of $18 \%$ observed in this study accompanied by an additional $19 \%$ of patients presenting with a CSA of over five per hour during CPAP introduction suggests that CompSAS is considerably more common in those with CHF, and that with increased numbers of patients with CHF being screened and treated for OSA, it will be an increasing clinical problem associated with CompSAS. In this study, patients with CompSAS had lower diastolic blood pressure, a lower rate of diuretic use, and a higher New York Heart Association classification than patients without CompSAS.

Many studies investigated the prevalence and natural course of CompSAS, and the prevalence varies from about $1 \%$ to as much as about $20 \%$ (see Table 1 ). There may be genetic, environmental, or cultural differences among the patients, and the prevalence of CompSAS in a given patient population would vary depending on the specific diagnostic criteria applied. Currently, most studies on CompSAS have shortcomings. For example, classification of CompSAS in some studies was based on split-night studies. It is conceivable that a half-night CPAP titration is not representative of the whole night, and in a split-night study, placement of the mask and a rapidly escalating pressure for hasty titration during the second half of the night could be disruptive to sleep, resulting in arousals and transitions in sleep stages with consequent fluctuation in $\mathrm{PCO}_{2}$, which could promote instability of breathing. Furthermore, most studies were conducted retrospectively and with small sample sizes. 


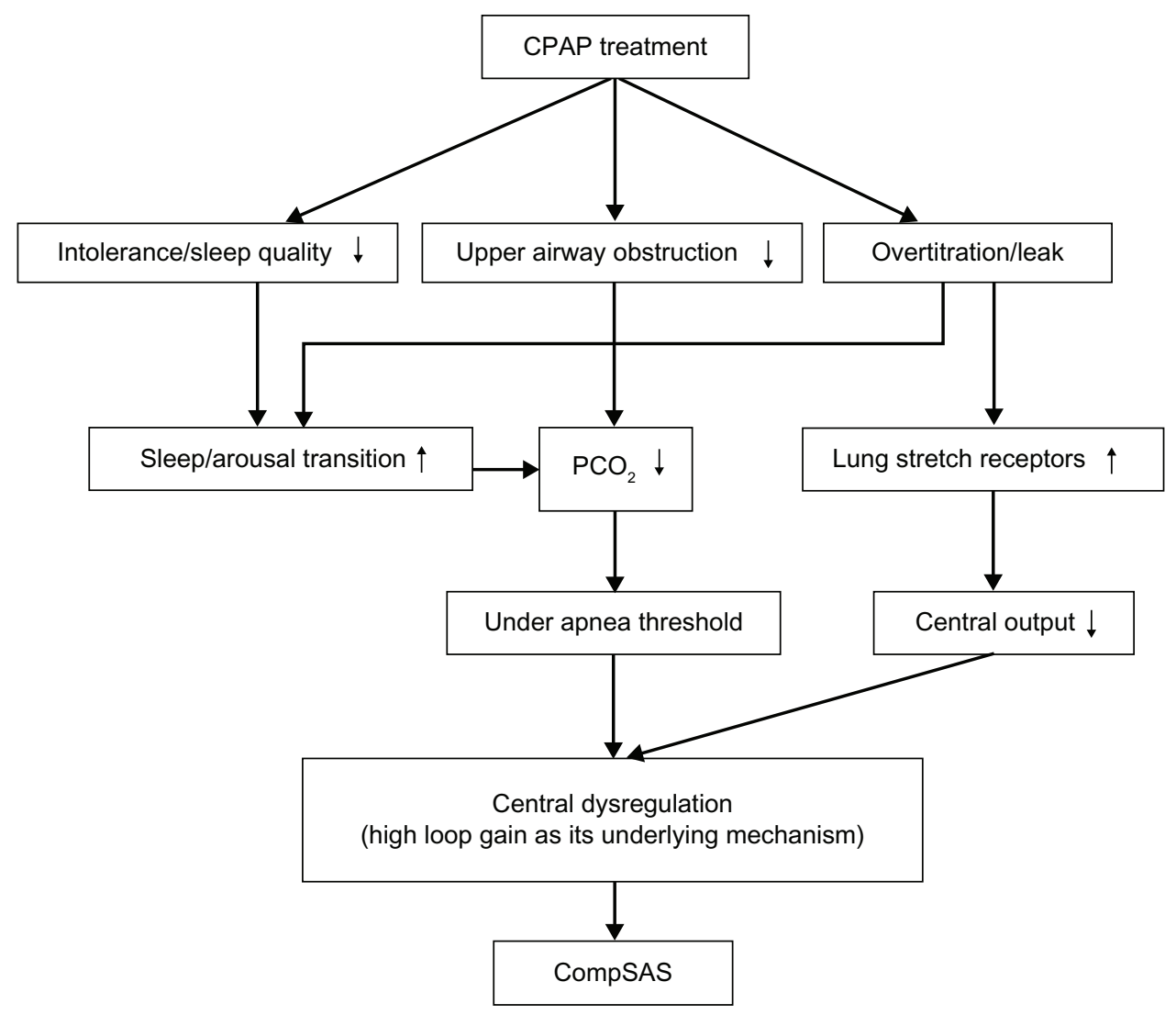

Figure I Potential mechanisms for CompSAS.

Abbreviations: CPAP, continuous positive airway pressure; CompSAS, complex sleep apnea syndrome.

Patients with CompSAS have clinical features similar to those patients with OSA, but they also exhibit breathing patterns close to patients with CSA. From some perspectives, their clinical features lie between those of patients with OSA and CSA.

Most studies suggest that CompSAS patients are, on average, middle-aged, and there is no significant difference between CompSAS and OSA. ${ }^{4,29,30,33,36}$ But in a prospective study of 675 patients, 82 CompSAS patients were significantly older $(59.8 \pm 9.7$ years versus [vs] $55.4 \pm 11.6$ years,

Table I The prevalence of complex sleep apnea syndrome

\begin{tabular}{lllll}
\hline Studies & $\begin{array}{l}\text { Reported } \\
\text { year }\end{array}$ & Country & $\begin{array}{l}\text { Included } \\
\text { patients, } \mathbf{n}\end{array}$ & $\begin{array}{l}\text { Prevalence, } \\
\%\end{array}$ \\
\hline $\begin{array}{l}\text { Morgenthaler } \\
\text { et al }^{4}\end{array}$ & 2006 & US & 233 & 15.0 \\
Lehman et al $^{29}$ & 2007 & Australia & 99 & 13.1 \\
Dernaika et al $^{30}$ & 2007 & US & 116 & 19.8 \\
Endo et a $^{33}$ & 2008 & Japan & 1312 & 5.0 \\
Kuzniar et al $^{34}$ & 2008 & US & 200 & 6.5 \\
Javaheri et al $^{35}$ & 2009 & US & 1286 & 6.5 \\
Yaegashi et al $^{36}$ & 2009 & Japan & 297 & 5.7 \\
Cassel et al $^{37}$ & 2011 & Germany & 675 & 12.2 \\
Westhoff et al $^{38}$ & 2012 & Germany & 1776 & 0.56 \\
\hline
\end{tabular}

$P=0.001) \cdot{ }^{37}$ CompSAS tends to occur among men. In a retrospective study among Japanese patients, the prevalence of CompSAS among males and females with OSA was $5.3 \%$ and $1.1 \%$, respectively. ${ }^{33}$ Morgenthaler et $\mathrm{al}^{4}$ found that $81 \%$ of patients with CompSAS were men. Male sex was more common in patients with CompSAS than in those with pure OSAS or CSA ( $81 \%$ vs $60 \%$ vs $43 \%$; $P=0.027$ ). Lehman et $\mathrm{al}^{29}$ also reported that the proportion of men was higher in the CompSAS group ( $92 \%$ vs $79.1 \%, P<0.01$ ). Like with OSA, patients with CompSAS are often obese. In most epidemiologic investigation, there was no difference between the CompSAS and OSAS groups regarding body mass index (BMI). ${ }^{29,30,33,37}$ But Pusalavidyasagar et al ${ }^{39}$ demonstrated that BMI in CompSAS was lower when compared with OSAS patients. Adversely, Yaegashi et $\mathrm{al}^{36}$ found that CompSAS patients showed a tendency toward a higher BMI when compared with an OSAS group. A racial difference was thought to be one of the potential reasons for the differences. CompSAS patients may be less prone to having excessive daytime sleepiness than those with OSAS. Kuzniar et $a{ }^{34}$ reported that CompSAS patients had mild daytime hypersomnolence with an Epworth Sleepiness Score of 10 (interquartile range, 9 13). 
Most reports demonstrate that it is difficult to distinguish definitely between CompSAS and OSA using only diagnostic polysomnography (PSG), because patients with CompSAS are generally similar to those with OSA until CPAP is applied. However, there may be some special characteristics in the PSG from CompSAS patients. In retrospective research in 297 patients who underwent a CPAP titration study for OSAS, 17 patients had either an emergence or persistence of CSA. ${ }^{36}$ There was no statistical difference between the CompSAS group and the OSAS group in apnea-hypopnea index (AHI), CAI, obstructive apnea index (OAI), mixed apnea index (MAI), 3\% oxygen desaturation index (3\% ODI), cumulative percentage of sleep time with $\mathrm{SpO}_{2}$ below $90 \%$ (CT90), sleep architecture, and arousal index on PSG. In the comparison regarding the sleep body position or sleep stage, both the total CAI and the CAI in the supine position during nonrapid eye movement (NREM) sleep were significantly higher in CompSAS patients than those in the OSAS group. Morgenthaler et al, ${ }^{4}$ Lehman et $\mathrm{al}^{29}{ }^{29}$ and Endo et $\mathrm{al}^{33}$ all found that patients with CompSAS had a higher AHI, CAI, and MAI than those with OSAS. Cassel et $\mathrm{al}^{37}$ found that there was a trend toward higher arousal index, and significantly more awakenings were observed in CompSAS patients. In all these studies, CompSAS patients had a higher CAI and showed that the majority of central apneas occurred during NREM sleep in PSG. During titration, CPAP led to clear improvement in AHI for patients with OSAS but incomplete resolution of sleep-disordered breathing in patients with CompSAS.

In CompSAS, most CSA events during initial CPAP titration are transient and they may disappear after continued CPAP use. Only a few CSA events persist despite continued CPAP follow-up, which is defined as CPAP-persistent CSA. In contrast, there are also some patients who do not have CSA in initial CPAP titration but who develop CSA during long-term CPAP treatment. It is suggested that CSA events occurring during CPAP titration appear to represent a benign and transient phenomenon. ${ }^{30} \mathrm{CPAP}$ "nonresponders" (CPAP-persistent CSA) might have higher initial sleepiness, a trend toward lower BMI, and more severe OSA than "CPAP responders," and use of opioids could be a potential risk factor. ${ }^{34,35}$

\section{Treatment}

Perhaps the most crucial concern for patients with CompSAS is whether there is a preferential treatment approach. The coexistence of obstruction and ventilatory dysregulation that characterizes CompSAS suggests a need to correct both of these mechanisms for successful treatment. In parallel to
OSA patients, continued apnea activity may be associated with adverse health effects, such as hypertension, cardiovascular disease, and stroke. ${ }^{40,41}$ Goals of treatment of CompSAS are normalization of the $\mathrm{AHI}$ and sleep architecture in order to reduce the complications and improve quality of life. Patients with CompSAS may have a poor initial experience with CPAP. But some CSA events during initial CPAP titration are transient and they disappear after continued CPAP use. So CPAP is still the first-line treatment for the CompSAS. Other than CPAP, various therapeutic options have been studied, including adaptive servo-ventilation (ASV), bi-level positive airway pressure (bi-level PAP), supplemental oxygen, $\mathrm{CO}_{2}$, or medication.

\section{CPAP}

CPAP devices produce steady pressure that does not change during the respiratory cycle. It is the first-line noninvasive treatment for OSAS, and can almost completely suppress obstructive respiratory events. But CPAP typically does not acutely resolve central apnea activity. Patients with CompSAS may have a poor initial experience with CPAP and thus may be nonadherent with therapy. Using retrospective data and OSAS patients as a comparison group, Pusalavidyasagar et $\mathrm{al}^{39}$ documented that although patients in both groups had a similar diagnostic AHI, CompSAS patients had a significantly higher AHI during the CPAP titration (CompSAS AHI on CPAP 24.6 \pm 21.6 vs OSAS AHI on CPAP $2.1 \pm 2.7$ ), and most of the residual respiratory disturbance was from central apneas that emerged on CPAP. Mean time to the first follow-up was shorter in CompSAS patients (46.2 \pm 47.3 days vs $53.8 \pm 36.8$ days), and interface problems were more common in CompSAS patients, especially air hunger/dyspnea (8.8\% vs $0.8 \%)$ and inadvertent mask removal $(17.7 \%$ vs $2.6 \%)$. Some researchers suggest that most CSA events can disappear after continued CPAP use. It is still not clear what proportion of patients with CompSAS may improve over time with continued CPAP treatment. Dernaika et al, ${ }^{30}$ in their prospective case-control study, documented the disappearance of central apnea activity with CPAP in $12(86 \%)$ of 14 patients with CompSAS over 2-3 months. The investigators stated that CSA events occurring during CPAP titration were transient and self-limited, whereas only one patient with diastolic dysfunction on baseline transthoracic echocardiography showed continued CSA events. Unfortunately, the applicability of their data is limited because they excluded patients with any significant comorbidities, including CHF by history or previous echocardiography, chronic obstructive pulmonary disease or other 
significant lung disease, daytime hypercapnia or hypoxemia, cerebrovascular disease, seizure disorder, or a history of use of benzodiazepines, narcotics, or illicit drugs. In a retrospective case series, Kuzniar et $\mathrm{al}^{34}$ evaluated 13 patients who had CompSAS during the first overnight CPAP titration. Repeat therapeutic PSGs were performed after 195 (49-562) days. On the follow-up study, seven of 13 patients reached AHI $<10$. The low number of patients and retrospective character of data collection are the main limitations of this study. Cassel et $\mathrm{al}^{37}$ investigated 675 patients with OSA receiving CPAP treatment. During the baseline CPAP night, 82 patients had CompSAS. The follow-up evaluations took place after a median of 14 weeks, and 30 patients fulfilled the criteria for CompSAS. The prevalence of CompSAS was significantly reduced from $12.2 \%$ to $6.9 \%$. In a large retrospective study of 1286 patients with a diagnosis of OSA who underwent titration with CPAP, CompSAS occurred in 84 patients $(6.5 \%)$. However, after 8 weeks of CPAP therapy, they estimate that $1.5 \%$ of the patients with OSA continued to have CompSAS with long-term use of CPAP. ${ }^{35}$ From these very limited data, it seems likely that most CompSAS patients will improve completely with long-term use of CPAP. This variability in CPAP response is probably due to heterogeneity in the CompSAS group or to variable factors governing adaptation that are not yet well understood. However, how to distinguish patients who might stabilize over time from those who will suffer ongoing complex apnea activity is unknown, and the time required for adaptation of ventilation is also unknown. Patients who have a bad initial experience with CPAP have a worse adherence to therapy, and those who fail with CPAP compliance over longer periods will not enjoy benefits of treatment while awaiting adaptation.

Adding oxygen to CPAP may result in better control of CSA and clearance of CompSAS, likely via reduction of the hypoxic respiratory drive. However, limited data exist regarding combination therapy with CPAP and oxygen. ${ }^{42}$ Patients with comorbidities requiring oxygen therapy independent of their CompSAS (hypoxemic patients with chronic pulmonary and cardiac diseases) may be good candidates for a trial of CPAP with oxygen. ${ }^{43}$

Combining CPAP with added carbon dioxide has been shown to correct the CSA pattern in a study. Thomas et $\mathrm{al}^{44}$ reported successful treatment using a prototype device, the positive airway pressure gas modulator. In their case series, they selected six adult men with severe poorly controlled mixed sleep-disordered breathing in the absence of renal or heart failure. The AHI before treatment was $66 \pm 14.5 / \mathrm{h}$ and on best treatment was $43 \pm 9 / \mathrm{h}$. Addition of $0.5 \%$ to $1 \%$ carbon dioxide using a positive airway pressure gas modulator rapidly immediately corrected CSA, the residual AHI was in the normal range $(<5 / \mathrm{h})$, and no adverse effects on overall sleep architecture were noted. But the data were limited and the sample was small. Further randomized trials will be required to assess the feasibility.

Increasing in physiological dead space has been reported to control nonobstructive sleep-disordered breathing, although it has not been previously used with positive airway pressure therapy. ${ }^{45,46}$ Thomas $^{47}$ reported a CHF patient who improved sleep-disordered breathing by positive airway pressure with added dead space successfully. This was achieved by using a nonvented oronasal mask and 4 6 inches of additional standard tubing followed by an exhalation valve. The treatment was well tolerated with no increased sensation of dyspnea or respiratory rate. When used with positive airway pressure, small amounts of added dead space (150 200 cc total, estimated $0.3 \% \sim 0.7 \%$ inhaled $\mathrm{CO}_{2}$ ) seem adequate to result in therapeutic benefit in CompSAS patients.

\section{Bi-level PAP}

There are still some debates as to whether bi-level PAP is useful for CompSAS. A retrospective review evaluated 95 of 719 patients who used a bi-level PAP device for central apnea over a 2 -year period. ${ }^{48}$ Eighty of the 95 patients treated with bi-level PAP were also treated with CPAP. Bi-level PAP was more likely to worsen than improve central apnea. Central apneas were more likely to worsen with bi-level PAP than with CPAP. Other research included 39 patients with CompSAS and found that there was no difference in any of the polysomnographic indices on CPAP and bi-level PAP. ${ }^{49}$ However, Morgenthaler et $\mathrm{al}^{7}$ reported that bi-level PAP was effective in normalizing breathing and sleep parameters. So further systematic studies on the using of bi-level PAP are needed.

\section{ASV}

ASV is a novel form of positive airway pressure unit that continuously monitors the patient's breathing pattern in exquisite detail. The clinician sets the end expiratory pressure, and the device determines the magnitude and timing of ventilatory support during inspiration. Whenever it detects significant reductions or pauses in breathing, it intervenes with just enough support to maintain the patient's breathing. When the patient's breathing problem ends, the machine backs out gently. Also, when the patient's breathing is stable, ASV provides just enough pressure support to help maintain airway patency. ${ }^{50}$ Currently, there are two models of ASV, the ResMed 
VPAP-AdaptSV (ResMed Ltd, Bella Vista, NSW, Australia) and the Respironics BiPAP-AutoSV (Philips Healthcare, Andover, MA, USA). The benefit of ASV has been shown in patients with heart failure and CSA in both short and longterm studies, and many researchers suggest a future for this technology. ${ }^{51-56}$ ASV devices have been shown to be effective in controlling CompSAS activity. Bitter et al, ${ }^{32}$ in their research, offered ASV to all 34 patients with CompSAS, and the investigations were repeated at 3-monthly follow-up visits. Downloaded data from the device showed that the average AHI for the entire treatment period was $5.2 \pm 7.1 / \mathrm{h}$. Only in one patient was ASV unsuccessful in reducing AHI below $15 / \mathrm{h}$. In a retrospective case series of 18 subjects with CompSAS, Brown et $\mathrm{al}^{50}$ reported that ASV proved highly effective in eliminating central apneas as well as obstructive and mixed events. The AHI normalized from $48.5 \pm 30.2 / \mathrm{h}$ to $3.6 \pm 4.2 / \mathrm{h}$ with ASV. A successful ASV titration $($ AHI $\leq 10 / \mathrm{h})$ was achieved in $92 \%$ of patients, and $80 \%$ were stabilized using more stringent criteria for success $(\mathrm{AHI} \leq 5 / \mathrm{h})$. ASV also significantly improved sleep fragmentation. The respiratory arousal and total arousal indices decreased by $88 \%$ and $72 \%$, respectively. Furthermore, measures of oxygenation $\left(\mathrm{SpO}_{2}\right.$ nadir and $\mathrm{SpO}_{2}<90 \%$ ) improved with ASV. In a short-term randomized trial, a group of nine patients with CompSAS used both noninvasive positive pressure ventilation (NPPV) and ASV. Both NPPV and ASV improved the AHI compared with CPAP (AHI with CPAP $34.3 \pm 25.7$ vs NPPV $4.7 \pm 5.8$, and ASV $0.9 \pm 2.8)$. The ASV device seemed to be more effective than NPPV in resolving CompSAS activity. ${ }^{7}$ Allam et al ${ }^{42}$ also reported that ASV was more successful than either CPAP with oxygen or BiPAP-S/T. During diagnostic polysomnography, the median AHI was 48.0 events per hour. With CPAP, the median AHI decreased to 31 events per hour. BiPAP-S/T improved the AHI to 15.0 events per hour. CPAP with oxygen improved the AHI to ten events per hour. The most improvement occurred with ASV, which decreased the median AHI to five events per hour. During the follow-up period, the majority of contacted patients (73\%) reported improvement in sleep quality and/or daytime sleepiness. Kuzniar et $\mathrm{al}^{57}$ described their experience with patients using ASV in the treatment of CompSAS. Data of 76 patients with CompSAS who were prescribed a VPAP-AdaptSV or BiPAP-AutoSV in a nonrandomized parallel design were retrospectively analyzed. Thirty-five patients received a VPAP-AdaptSV device, and 41 patients were treated with BiPAP-AutoSV. On the titration study, the expiratory pressure required to control obstructive events was significantly lower in the VPAP-AdaptSV group than in the BiPAP-AutoSV group. Residual CAI was not significantly different. On follow-up of 4-6 weeks, 24 patients $(68.6 \%)$ treated with VPAP-AdaptSV and 32 patients (78\%) treated with BiPAP-AutoSV were using their device. Mean nightly use was 5.0 hours (2.8-6.4 hours) for the VPAP-AdaptSV group and 6.0 hours (3.5-7.2 hours) for the BiPAP-AutoSV group $(P=0.081)$. An improvement in Epworth Sleepiness Scale score was seen in the BiPAP-AutoSV group compared with the VPAP-AdaptSV group (4 [1-9] vs 2.5 [0-5], $P=0.02)$. The results of the study indicate that two servoventilation devices are a comparable means of controlling CompSAS and that compliance with them is high. Recently, Javaheri et $\mathrm{al}^{58}$ evaluated the therapeutic performance of a new auto servo-ventilation device (Philips Respironics autoSV Advanced, Best, The Netherlands) for the treatment of CompSAS. They found that BiPAP autoSV Advanced was more effective than conventional BiPAP-AutoSV in the treatment of sleep-disordered breathing. It is now believed that ASV devices may rapidly resolve the disorder with the potential of increasing early adherence to therapy. But pressure titration on ASV devices is somewhat more complicated than CPAP titration and requires greater proficiency in the technician. Furthermore, the availability of these devices may be limited owing to their high cost.

\section{Medication}

Acetazolamide is an effective treatment for CSA in heart failure, at high altitude, and in its idiopathic form. ${ }^{59,60}$ Acetazolamide administration in humans has been shown to inhibit the ventilatory response of the peripheral chemoreceptors but to enhance central chemosensitivity to $\mathrm{CO}_{2}$. Opioid therapy appears to have altered the $\mathrm{CO}_{2}$ apnea threshold in CompSAS patients. ${ }^{61,62}$ Glidewell et $\mathrm{al}^{63}$ reported the use of $250 \mathrm{mg}$ acetazolamide nightly at bedtime as an adjunct to CPAP therapy for a 41-year-old white woman under longacting opioid therapy with CompSAS. A positive response to the adjunctive use of acetazolamide in this case suggests that acetazolamide may have utility in the broader management of CompSAS related to chronic opioid therapy.

\section{Conclusion}

In most CompSAS cases, CSA events during initial CPAP titration are transient and they disappear after continued CPAP use. Because CompSAS patients have a poor initial experience with CPAP, they may be nonadherent with continued therapy. Treatment options like ASV are available that may rapidly resolve the disorder and relieve the symptoms of this disease with the potential of increasing early adherence to therapy. But not all CompSAS patients need an expensive and 
complicated device. Many questions about CompSAS remain unresolved, such as the mechanisms underlying CompSAS (though we have high loop gain theory that may shine some light), the prevalence of CompSAS, and which patients will finally resolve their CSA events along with CPAP use, and more further bench and clinical studies are needed.

\section{Acknowledgments}

This study was supported by grants from the National Natural Science Foundation of China (Nos 81270144, 30800507, $81170071)$. We are grateful for the information and correction from Danielle Speer and Ambrose Chiang at the Division of Pulmonary and Critical Care Medicine in Duke University Medical Center, Durham 27710, NC, USA.

\section{Disclosure}

None of the authors has a financial relationship with a commercial entity that has an interest in the subject of this manuscript.

\section{References}

1. Thomas RJ, Terzano MG, Parrino L, Weiss JW. Obstructive sleepdisordered breathing with a dominant cyclic alternating pattern a recognizable polysomnographic variant with practical clinical implications. Sleep. 2004;27(2):229-234.

2. Guilleminault C, Cummiskey J. Progressive improvement of apnea index and ventilatory response to $\mathrm{CO} 2$ after tracheostomy in obstructive sleep apnea syndrome. Am Rev Respir Dis. 1982;126(1):14-20.

3. Gilmartin GS, Daly RW, Thomas RJ. Recognition and management of complex sleep-disordered breathing. Curr Opin Pulm Med. 2005;11(6): 485-493.

4. Morgenthaler TI, Kagramanov V, Hanak V, Decker PA. Complex sleep apnea syndrome: is it a unique clinical syndrome? Sleep. 2006;29(9): 1203-1209.

5. Gay PC. Complex sleep apnea: it really is a disease. J Clin Sleep Med. 2008;4(5):403-405.

6. Malhotra A, Bertisch S, Wellman A. Complex sleep apnea: it isn't really a disease. J Clin Sleep Med. 2008;4(5):406-408.

7. Morgenthaler TI, Gay PC, Gordon N, Brown LK. Adaptive servoventilation versus noninvasive positive pressure ventilation for central, mixed, and complex sleep apnea syndromes. Sleep. 2007;30(4): 468-475.

8. Fletcher EC. Recurrence of sleep apnea syndrome following tracheostomy. A shift from obstructive to central apnea. Chest. 1989;96(1):205-209.

9. Kuźniar TJ, Kovačević-Ristanović R, Freedom T. Complex sleep apnea unmasked by the use of a mandibular advancement device. Sleep Breath. 2011;15(2):249-252.

10. Corcoran S, Mysliwiec V, Niven AS, Fallah D. Development of central sleep apnea after maxillofacial surgery for obstructive sleep apnea. J Clin Sleep Med. 200915;5(2):151-153.

11. Goldstein C, Kuzniar TJ. The emergence of central sleep apnea after surgical relief of nasal obstruction in obstructive sleep apnea. J Clin Sleep Med. 2012;8(3):321-312.

12. Malhotra A, Owens RL. What is central sleep apnea? Respir Care. 2010;55(9):1168-1178.

13. Meza S, Mendez M, Ostrowski M, Younes M. Susceptibility to periodic breathing with assisted ventilation during sleep in normal subjects. J Appl Physiol. 1998;85(5):1929-1940.
14. Skatrud JB, Dempsey JA. Interaction of sleep state and chemical stimuli in sustaining rhythmic ventilation. J Appl Physiol. 1983;55(3): $813-822$.

15. Dempsey JA. Crossing the apnoeic threshold: causes and consequences. Exp Physiol. 2005;90(1):13-24.

16. Khoo MC, Kronauer RE, Strohl KP, Slutsky AS. Factors inducing periodic breathing in humans: a general model. J Appl Physiol. 1982;53(3):644-659.

17. White DP. Pathogenesis of obstructive and central sleep apnea. Am J Respir Crit Care Med. 2005;172(11):1363-1370.

18. Wellman A, Malhotra A, Fogel RB, Edwards JK, Schory K, White DP. Respiratory system loop gain in normal men and women measured with proportional-assist ventilation. J Appl Physiol. 2003;94(1):205-212.

19. Meza S, Younes M. Ventilatory stability during sleep studied with proportional assist ventilation (PAV). Sleep. 1996;19(Suppl 10): S164-166.

20. Cherniack NS. Respiratory dysrhythmias during sleep. $N$ Engl J Med. 1981;305(6):325-330.

21. Hudgel DW, Gordon EA, Thanakitcharu S, Bruce EN. Instability of ventilatory control in patients with obstructive sleep apnea. Am J Respir Crit Care Med. 1998;158(4):1142-1149.

22. Khoo MC. Determinants of ventilatory instability and variability. Respir Physiol. 2000;122(2-3):167-182.

23. Younes M, Ostrowski M, Thompson W, Leslie C, Shewchuk W. Chemical control stability in patients with obstructive sleep apnea. Am J Respir Crit Care Med. 2001;163(5):1181-1190.

24. Wellman A, Jordan AS, Malhotra A, et al. Ventilatory control and airway anatomy in obstructive sleep apnea. Am J Respir Crit Care Med. 2004;170(11):1225-1232.

25. Eckert DJ, Jordan AS, Merchia P, Malhotra A. Central sleep apnea: pathophysiology and treatment. Chest. 2007;131(2):595-607.

26. Skatrud JB, Dempsey JA, Badr S, Begle RL. Effect of airway impedance on $\mathrm{CO} 2$ retention and respiratory muscle activity during NREM sleep. J Appl Physiol. 1988;65(4):1676-1685.

27. Jordan AS, McEvoy RD, Edwards JK, Schory K, Yang CK, Catcheside PG, et al. The influence of gender and upper airway resistance on the ventilatory response to arousal in obstructive sleep apnoea in humans. J Physiol. 2004;558(Pt 3):993-1004.

28. Nakazaki C, Noda A, Yasuda Y, Nakata S, Koike Y, Yasuma F, et al. Continuous positive airway pressure intolerance associated with elevated nasal resistance is possible mechanism of complex sleep apnea syndrome. Sleep Breath. 2012;16(3):747-752.

29. Lehman S, Antic NA, Thompson C, Catcheside PG, Mercer J, McEvoy RD. Central sleep apnea on commencement of continuous positive airway pressure in patients with a primary diagnosis of obstructive sleep apnea-hypopnea. J Clin Sleep Med. 2007;3(5):462-466.

30. Dernaika T, Tawk M, Nazir S, Younis W, Kinasewitz GT. The significance and outcome of continuous positive airway pressure-related central sleep apnea during split-night sleep studies. Chest. 2007;132(1):81-87.

31. De Paolis F, Colizzi E, Milioli G, et al. Complex sleep apnea syndrome in stroke patients. Sleep Med. 2013;14(2):224.

32. Bitter T, Westerheide N, Hossain MS, Lehmann R, Prinz C, Kleemeyer A, et al. Complex sleep apnoea in congestive heart failure. Thorax. 2011;66(5):402-407.

33. Endo Y, Suzuki M, Inoue Y, et al. Prevalence of complex sleep apnea among Japanese patients with sleep apnea syndrome. Tohoku J Exp Med. 2008;215(4):349-354.

34. Kuzniar TJ, Pusalavidyasagar S, Gay PC, Morgenthaler TI. Natural course of complex sleep apnea - a retrospective study. Sleep Breath. 2008;12(2):135-139.

35. Javaheri S, Smith J, Chung E. The prevalence and natural history of complex sleep apnea. J Clin Sleep Med. 2009;5(3):205-211.

36. Yaegashi H, Fujimoto K, Abe H, Orii K, Eda S, Kubo K. Characteristics of Japanese patients with complex sleep apnea syndrome: a retrospective comparison with obstructive sleep apnea syndrome. Intern Med. 2009;48(6):427-432. 
37. Cassel W, Canisius S, Becker HF, Leistner S, Ploch T, Jerrentrup A, et al. A prospective polysomnographic study on the evolution of complex sleep apnoea. Eur Respir J. 2011;38(2):329-337.

38. Westhoff M, Arzt M, Litterst P. Prevalence and treatment of central sleep apnoea emerging after initiation of continuous positive airway pressure in patients with obstructive sleep apnoea without evidence of heart failure. Sleep Breath. 2012;16(1):71-78.

39. Pusalavidyasagar SS, Olson EJ, Gay PC, Morgenthaler TI. Treatment of complex sleep apnea syndrome: a retrospective comparative review. Sleep Med. 2006;7(6):474-479.

40. O'Connor GT, Caffo B, Newman AB, Quan SF, Rapoport DM, Redline S, et al. Prospective study of sleep-disordered breathing and hypertension: the Sleep Heart Health Study. Am J Respir Crit Care Med. 2009;179(12):1159-1164.

41. Levy AP, Zhang L, Miller-Lotan R, et al. Haptoglobin phenotype, sleepdisordered breathing, and the prevalence of cardiovascular disease: the Sleep Heart Health Study. Sleep. 2005;28(2):207-213.

42. Allam JS, Olson EJ, Gay PC, Morgenthaler TI. Efficacy of adaptive servoventilation in treatment of complex and central sleep apnea syndromes. Chest. 2007;132(6):1839-1846.

43. Kuźniar TJ, Morgenthaler TI. Treatment of complex sleep apnea syndrome. Curr Treat Options Neurol. 2008;10(5):336-341.

44. Thomas RJ, Daly RW, Weiss JW. Low-concentration carbon dioxide is an effective adjunct to positive airway pressure in the treatment of refractory mixed central and obstructive sleep-disordered breathing. Sleep. 2005;28(1):69-77.

45. Khayat RN, Xie A, Patel AK, Kaminski A, Skatrud JB. Cardiorespiratory effects of added dead space in patients with heart failure and central sleep apnea. Chest. 2003;123(5):1551-1560.

46. Xie A, Rankin F, Rutherford R, Bradley TD. Effects of inhaled CO2 and added dead space on idiopathic central sleep apnea. J Appl Physiol. 1997;82(3):918-926.

47. Thomas RJ. Effect of added dead space to positive airway pressure for treatment of complex sleep-disordered breathing. Sleep Med. 2005;6(2):177-178.

48. Johnson KG, Johnson DC. Bilevel positive airway pressure worsens central apneas during sleep. Chest. 2005;128(4):2141-2150.

49. Kuźniar TJ, Kasibowska-Kuźniar K, Freedom T. Trials of bilevel positive airway pressure - spontaneous in patients with complex sleep apnoea. Pneumonol Alergol Pol. 2012;80(3):214-219.

50. Brown SE, Mosko SS, Davis JA, Pierce RA, Godfrey-Pixton TV. A retrospective case series of adaptive servoventilation for complex sleep apnea. J Clin Sleep Med. 2011;7(2):187-195.

51. Pepperell JC, Maskell NA, Jones DR, et al. A randomized controlled trial of adaptive ventilation for Cheyne-Stokes breathing in heart failure. Am J Respir Crit Care Med. 2003;168(9):1109-1114.
52. Philippe C, Stoïca-Herman M, Drouot X, Raffestin B, Escourrou P, Hittinger L, et al. Compliance with and effectiveness of adaptive servoventilation versus continuous positive airway pressure in the treatment of Cheyne-Stokes respiration in heart failure over a six month period. Heart. 2006;92(3):337-342.

53. Brown LK. Filling in the gaps: the role of noninvasive adaptive servoventilation for heart failure-related central sleep apnea. Chest. 2008;134(1):4-7.

54. Morgenthaler TI. The quest for stability in an unstable world: adaptive servoventilation in opioid induced complex sleep apnea syndrome. J Clin Sleep Med. 2008;4(4):321-323.

55. Ramar K, Ramar P, Morgenthaler TI. Adaptive servoventilation in patients with central or complex sleep apnea related to chronic opioid use and congestive heart failure. J Clin Sleep Med. 2012;8(5):569-576.

56. Randerath WJ, Galetke W, Stieglitz S, Laumanns C, Schäfer T. Adaptive servo-ventilation in patients with coexisting obstructive sleep apnoea/ hypopnoea and Cheyne-Stokes respiration. Sleep Med. 2008;9(8): 823-830.

57. Kuzniar TJ, Patel S, Nierodzik CL, Smith LC. Comparison of two servo ventilator devices in the treatment of complex sleep apnea. Sleep Med. 2011;12(6):538-541.

58. Javaheri S, Goetting MG, Khayat R, Wylie PE, Goodwin JL, Parthasarathy S. The performance of two automatic servo-ventilation devices in the treatment of central sleep apnea. Sleep. 2011;34(12): 1693-1698.

59. Javaheri S. Acetazolamide improves central sleep apnea in heart failure: a double-blind, prospective study. Am J Respir Crit Care Med. 2006; 173(2):234-237.

60. Swenson ER, Hughes JM. Effects of acute and chronic acetazolamide on resting ventilation and ventilatory responses in men. J Appl Physiol. 1993;74(1):230-237.

61. Edwards BA, Sands SA, Eckert DJ, White DP, Butler JP, Owens RL, et al. Acetazolamide improves loop gain but not the other physiological traits causing obstructive sleep apnoea. J Physiol. 2012;590(Pt 5): 1199-1211.

62. Fontana M, Emdin M, Giannoni A, Iudice G, Baruah R, Passino C. Effect of acetazolamide on chemosensitivity, Cheyne-Stokes respiration, and response to effort in patients with heart failure. Am J Cardiol. 2011;107(11):1675-1680.

63. Glidewell RN, Orr WC, Imes N. Acetazolamide as an adjunct to CPAP treatment: a case of complex sleep apnea in a patient on long-acting opioid therapy. J Clin Sleep Med. 2009;5(1):63-64.
Patient Preference and Adherence

\section{Publish your work in this journal}

Patient Preference and Adherence is an international, peer-reviewed, open access journal focusing on the growing importance of patient preference and adherence throughout the therapeutic continuum. Patient satisfaction, acceptability, quality of life, compliance, persistence and their role in developing new therapeutic modalities and compounds to

\section{Dovepress}

optimize clinical outcomes for existing disease states are major areas of interest. This journal has been accepted for indexing on PubMed Central. The manuscript management system is completely online and includes a very quick and fair peer-review system. Visit http://www.dovepress.com/ testimonials.php to read real quotes from published authors. 